\title{
OXIDE DISPERSION STRENGTHENED SUPERALLOYS: TIIE ROLE OF GRAIN STRUCTURE AND DISPERSION DURING HIGH TEMPERATURE LOW CYCLE FATIGUE
}

\author{
D. M. Elzey and E. Arzt \\ Max-Planck-Institut für Metallforschung \\ Seestrasse 92, D 7000 Stuttgart 1 \\ Federal Republic of Germany
}

\begin{abstract}
The mechanisms leading to failure during high temperature, LCF and creep-fatigue are presented and discussed for two representative, commercial ODS (Oxide DispersionStrengthened) superalloys, Inconel MA 754 and MA 6000. The fatigue behavior of these alloys is compared with that of conventional (non-ODS) superalloys of nearly identical elemental composition. The behavioral differences may be understood on the basis of the two primary microstructural differences between ODS and non-ODS, namely, grain structure and the fine particle dispersion itself. It is found that recrystallization defects in the form of fine grains are the primary cause of crack initiation in the ODS materials. The results are discussed in light of previous creep and fatigue studies of dispersion-strengthened alloys.
\end{abstract}




\section{Introduction}

Alloys strengthened through inclusion of a fine dispersion of oxide particles have received considerable attention due to their exceptional creep properties. As a consequence, our understanding of creep-related phenomena in ODS alloys is now comparable with that of currently used, non-dispersion strengthened superalloys. However there have appeared relatively few studies in the open literature whose subject has been the behavior of ODS materials during high temperature fatigue. In the following, the results of high temperature fatigue and creep-fatigue experiments obtained for two commercially available ODS superalloys will be presented and discussed in light of previous fatigue studies and our current understanding of the creep behavior of ODS materials.

Essentially, ODS alloys are distinguished from conventional superalloys by the dispersion of fine oxide particles and by an elongated grain shape, which develops during a recrystallization heat treatment. This particular grain structure enhances the high temperature deformation behavior by inhibiting intergranular damage accumulation. This is accomplished by increased constraint in the neighborhood of cavitating, transverse grain boundaries and by increased tortuosity of intergranular crack paths (1). It has also been quite well demonstrated how an oxide dispersion improves high temperature creep strength. The movement of dislocations is impeded by the non-shearable dispersoid particles resulting in a threshold stress below which creep rates are negligible $(2,3,4)$.

It is to be expected that the high temperature cyclic behavior of ODS alloys is also strongly influenced by the dispersion and grain morphology. Practically all investigators into the fatigue behavior of ODS materials have reported improved fatigue damage resistance, (e.g. 5-7). It has been commonly reported that the amount of slip observed is less for dispersion-strengthened material and that slip character becomes more wavy or discontinuous $(8,9,10,11)$. TEM observations have indicated that dislocation cell structures either do not form or that their formation and diameter are determined by particle geometry $(10,12,6,13,14)$.

Low frequency fatigue at high temperatures entails conditions which are sufficient for the operation of time dependent damage mechanisms such as those present during creep. It is clear that such processes, which normally lead to intergranular fracture, are made more difficult by an elongated grain structure during cyclic loading just as they are during monotonic loading, (e.g. 6,13). However, the creep-fatigue behavior of dispersion-strengthened alloys has not been studied in any detail to date. In the following, some results of creepfatigue tests of MA 6000 are discussed which reveal aspects useful for the optimization of alloy behavior under high temperature creep and fatigue conditions.

\section{Experimental}

Present experimental work has been concentrated on the two yttrium-oxide dispersion-strengthened superalloys Inconel MA 754 and MA 6000 . Both alloys are produced by INCO Alloys International, by the mechanical alloying process (15). The performance and behavior of each ODS alloy has been compared with that of a conventional (cast or wrought non-ODS) alloy of similar elemental composition. The compositions as determined for both ODS and non-ODS counterpart alloys are given in table I along with other microstructural data.

MA 754 is strengthened by solid solution and by the dispersion. In addition, an elongated grain structure is obtained during heat treatment (see (16) for a more detailed description of the microstructure). In addition to solution strengthening, MA 6000 is strengthened at intermediate temperatures by gamma-prime $\mathrm{Ni}_{3}(\mathrm{Al}, \mathrm{Ti})$ precipitates while at temperatures above $900^{\circ} \mathrm{C}$, the dispersion is the dominant source of strength. A bi-modal distribution of grain sizes exists in MA 6000; large grains with lengths on the order of 1-2 centimeters and grain aspect ratios $(\mathrm{GAR})>20$ account for some $95 \%$ of the volume, while the remainder comprises a distribution of much smaller grains with lengths ranging from $100 \mu \mathrm{m}$ to 1 millimeter and GAR's between 1 and 20. For a more detailed description 
of the microstructure of MA 6000 the reader is referred to (17) and (18).

Low cycle fatigue tests have been carried out using total strain control with total or inelastic strain limits in the temperature range from 750 to $1100{ }^{\circ} \mathrm{C}$. Symmetric and asymmetric waveforms were chosen in conjunction with test frequencies such that the prevailing damage mode would be either of fatigue-type or mixed creep-fatigue. Creep-fatigue cycle forms included tensile hold-times and slow tensile loading followed by fast compression, commonly referred to as 'slow-fast'. Samples from tests run to physical separation of the specimen as well as interrupted experiments were then subjected to optical, scanning electron and transmission electron microscopy. Further experimental details will be given elsewhere (19).

Table I. Elemental Composition of Materials and Microstructural Data

\begin{tabular}{|c|c|c|c|c|c|c|c|c|c|c|c|c|c|}
\hline Alloy & $\mathrm{Ni}$ & $\mathrm{Cr}$ & $\mathrm{Fe}$ & $\mathrm{Al}$ & $\mathrm{Ti}$ & W & Mo & Co & $\mathrm{Ta}$ & $\mathrm{C}$ & B & $\mathrm{Zr}$ & $\mathrm{Nb} \mathrm{Y}_{2} \mathrm{O}_{3}$ \\
\hline MA 6000 & Bal & 15.5 & - & 4.5 & 2.5 & 3.8 & 2.0 & - & 1.9 & .06 & .01 & .16 & $5-1.1$ \\
\hline IN 738 & Bal & 15.9 & - & 3.5 & 3.5 & 2.5 & 1.6 & 8.3 & 1.6 & .09 & .01 & .5 & .7 \\
\hline MA 754 & Bal & 20.5 & .13 & .30 & .35 & - & - & - & - & .06 & - & - & $-\quad 0.5$ \\
\hline Nim 75 & Bal & 20 & $<5$ & .25 & .40 & - & - & - & - & .1 & - & - & $-\quad---$ \\
\hline & & \multicolumn{2}{|c|}{$\begin{array}{c}\text { Grain } \\
\text { Size }[\mathrm{mm}]\end{array}$} & \multicolumn{2}{|c|}{ GAR } & \multicolumn{2}{|c|}{$\begin{array}{l}\text { Particle } \\
\text { Dia [nm] }\end{array}$} & \multicolumn{4}{|c|}{$\begin{array}{c}\text { Particle } \\
\text { Spacing [nm] }\end{array}$} & \multicolumn{2}{|r|}{ Texture } \\
\hline MA 6000 & & \multicolumn{2}{|c|}{$5-20$} & \multicolumn{2}{|l|}{20} & \multicolumn{2}{|r|}{30} & \multicolumn{4}{|c|}{150} & \multicolumn{2}{|r|}{$<110>$} \\
\hline IN 738 & & \multirow{2}{*}{\multicolumn{2}{|c|}{$0.5^{2}-3.0$}} & 1 & & & - & \multirow{2}{*}{\multicolumn{4}{|c|}{125}} & & - \\
\hline MA 754 & & & & \multicolumn{2}{|l|}{10} & \multicolumn{2}{|r|}{15} & & & & & & $<100>$ \\
\hline $\operatorname{Nim} 75$ & & \multicolumn{2}{|l|}{0.1} & \multicolumn{2}{|l|}{1} & \multicolumn{2}{|r|}{-} & \multicolumn{4}{|c|}{-} & & - \\
\hline
\end{tabular}

Fatigue Behavior

Slip character: $O D S$ vs non-ODS

It has been well documented that gamma-prime-strengthened, $\mathrm{Ni}$-base superalloys are subject to the development of concentrated, planar slip bands during LCF $(20,21,22)$. The gamma-prime precipitates are sheared by such bands, causing a transition to coarse, planar slip (14). Such slip bands were found very infrequently in MA 6000 and only at high inelastic strain amplitudes $\left(\mathrm{N}_{\mathrm{f}}<100\right.$ cycles). In contrast with IN 738 (non-ODS counterpart for MA 6000), stage I cracks, which develop from coarse slip bands in nonODS alloys, have not been observed in MA 6000. Additionally, TEM micrographs often show individual dislocations which are pinned at the backside of dispersoid particles (figure 1), confirming the existence of an attractive interaction in a manner analogous to that observed for creep (23). No evidence of the formation of regular dislocation networks could be found, confirming the improved slip character.

Similarly, slip bands could not be resolved in fatigued MA 754 under any conditions of temperature and strain rate tested. MA 754 deforms macroscopically along planes of maximum shear stress (figure 2). Identical behavior has been reported for TD-Ni (nickel with thorium-oxide dispersion) $(24,10)$. This mode of deformation also results in a pronounced tendency for growing cracks to branch. By comparison, Nimonic 75 (non-ODS counterpart to MA 754), exhibits intense planar slip extending through entire grains under these conditions and initiates cracks at surface slip extrusions and at twins. Again, no stage I cracks were observed in the ODS material.

In agreement with earlier studies, these observations tend to confirm the hypothesis, e.g. (10), that planar slip deformation becomes dispersed as dislocation glide on planes oriented for slip is impeded by non-shearable particles. The subsequent activation of 


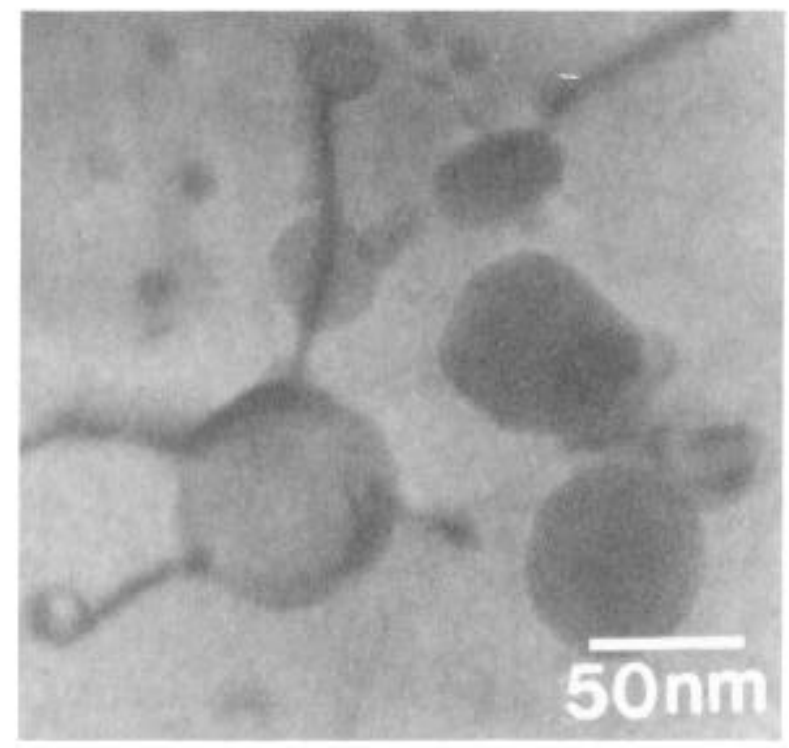

Figure 1: TEM showing dislocation configurations in fatigued MA 6000. Dispersoiddislocation interactions similar to those which have been described for creep are observed. $\left(850{ }^{\circ} \mathrm{C}\right.$, symmetric cycling, $10^{-3}$ $\left[\mathrm{s}^{-1}\right], \Delta \epsilon_{\mathrm{t}} / 2=0.4 \%$, failure after 100 cycles)

$\overline{1 \mathrm{~mm}}$

Figure 2: Surface of a cylindrical fatigue specimen of MA 754 illustrating damage on planes of maximum shear stress. $\left(1050^{\circ} \mathrm{C}\right.$, symmetric cycling, $10^{-3}\left[\mathrm{~s}^{-1}\right], \Delta \epsilon_{\mathrm{t}} / 2=0.4 \%$, failure after 180 cycles)

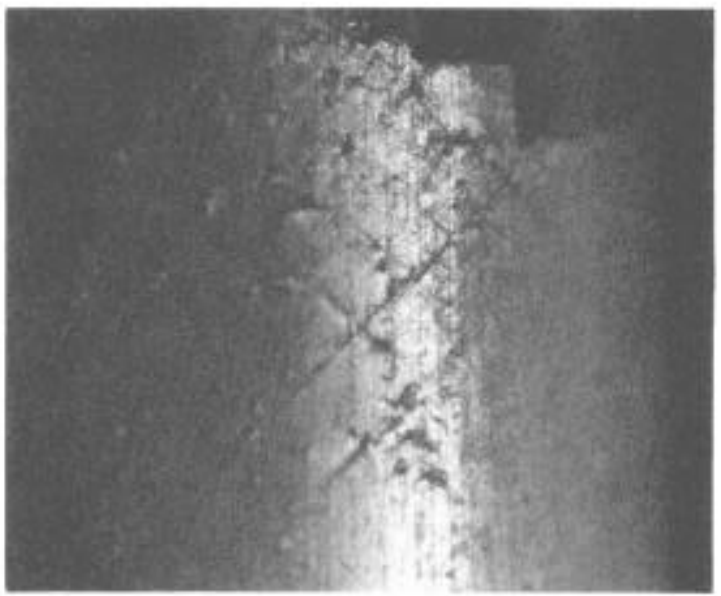

alternative slip systems homogenizes the plastic glide deformation. This process has sometimes been referred to as 'slip dispersal'. The metallurgical stability of the ceramic dispersoids in ODS alloys enables this mechanism of strengthening to be effective at temperatures in excess of $0.8 \mathrm{~T}_{\mathrm{m}}$.

\section{Grain boundaries as fatigue crack initiation sites}

The high degree of strengthening obtained within the grain interiors of ODS superalloys enhances the susceptibility of grain boundaries to various damage processes. Countering this imbalance is the highly elongated grain structure, characteristic of these materials. Large grain aspect ratios imply less grain boundary area lying normal to the applied stress within a given volume. The influence of GAR in determining creep damage rates has been well demonstrated for MA 6000 , where single crystal creep performance may be attained at GAR > $15-20(25,18,1)$.

Although the average GAR may be in excess of $15-20$, as is the case for the MA 6000 material tested in this study, local values of the GAR may be as low as 1-2. Such grain structure inhomogeneities, which take the form of relatively small included grains or pockets of finer grains sandwiched between elongated macro grains, might be expected to be the weakest link in the microstructural chain. That this is the case may be seen in figures 3 
and 4, which show crack initiation in MA 6000 during symmetric cycle LCF at $1 \mathrm{~Hz}$ and $850{ }^{\circ} \mathrm{C}$. The crack has initiated at the grain boundary of a fine grain located just beneath the sample surface. Initiation is usually observed to be on or near the sample surface but some internal initiation at fine grains has also been observed during the symmetric LCF of MA 6000 . Crack propagation to failure is fully transgranular. Although macroscopically MA 6000 exhibits a very strong $\langle 110\rangle$ texture, it has been shown that the incompletely recrystallized, fine grains are characterized by high misorientation (26). It is believed that the susceptibility of fine grains to fatigue damage is related to differences in the crystallographic orientation, which in some cases results in higher elastic stresses at fine grain boundaries during loading.



Figure 3: MA 6000 LCF fracture surface: crack initiation has occurred at the transverse boundary of a fine grain located near the test sample surface. $\left(850^{\circ} \mathrm{C}\right.$, symmetric cycling, $10^{-2}\left[\mathrm{~s}^{-1}\right]$, $\Delta \epsilon_{\mathrm{t}} / 2=0.3 \%$, failure after 5017 cycles)

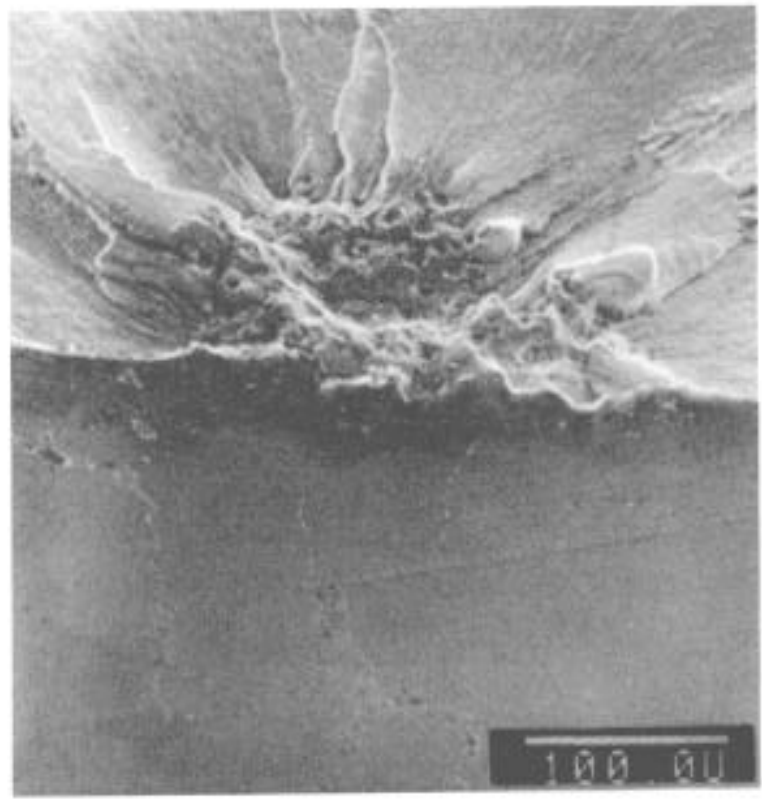

Figure 4: An axial section taken through the crack initiation point shown in the figure left. The etched boùndary of a fine grain is visible on the polished section surface.

Grain structure inhomogeneities are also present in MA 754 but since the average GAR is much less than for MA 6000 , the disparity between fine grains (GAR $\geq 1$ ) and the average GAR is also much smaller. Crack initiation is also complicated by the aforementioned shear deformation. It appears likely that the intersection of coarse shear bands at the sample surface can cause crack initiation although internal damage at fine grains has also been occasionally observed.

\section{$\underline{\text { Creep-Fatigue }}$}

Examination of the creep fracture behavior of MA 6000 has demonstrated the extreme susceptibility of grain structure inhomogeneities to cavitation damage $(18,1)$. This observation, and the fact that cracks are frequently seen to initiate at such relatively fine grains during symmetric-cycle LCF, indicates the likelihood that mixed creep-fatigue damage initiation should also occur at grain inhomogeneities. This hypothesis is well confirmed by the results of a number of 'slow-fast' LCF tests which were carried out on MA 6000. 
Figure 5 is a plane view of a fracture surface of an MA 6000 sample tested under 'slow-fast' $(\mathrm{S}-\mathrm{F})$ conditions at $850^{\circ} \mathrm{C}$. Closer inspection of the fracture surface reveals more than 20 individual, internal crack initiation sites, each surrounded by a radially expanding crack front (figure 6). That these initiation sites are indeed fine grains, is shown in figure 7. Metallographic examination of polished axial sections revealed the nucleation and growth of pores primarily on the transverse grain boundaries of fine grains. The presence of precipitate-free zones (PFZ) between pores indicates that pores grow by the stressdirected transport of atoms from the pore surface to the grain boundary. Detailed analysis of interrupted tests has shown that approximately $60-70 \%$ of the life is spent initiating cracks intergranularly in this manner.

The extent of cavitation damage accumulated during creep-fatigue exhibits a clear dependence on grain size. Fine grains were observed to be responsible for at least $80 \%$ of all crack initiation sites during creep-fatigue. Although the average GAR of finer grains is considerably less than that of the macrograins, no clear connection between the extent of cavitation damage and GAR could be ascertained among the population of fine grains. It should be noted that this observation does not conflict with the results of Zeizinger (18) and Arzt and Singer (25), who have shown that the creep rupture life of MA 6000 increases strongly as the average GAR increases. Stephens and Nix (27) have studied the creep behavior of MA 754 and also report the deleterious effect of a duplex grain morphology on the creep resistance. The enhanced grain boundary damage associated with fine grains could be due to the greater ease with which damage can be accommodated by grain sliding. However, the observation that fine grains with aspect ratios upto 20 are still highly prone to cavitation renders this explanation suspect. It appears more likely that, as mentioned previously in connection with LCF crack initiation, the crystallographic misorientation of fine grains with respect to the fully recrystallized macrograins enhances damage formation.

The subject of creep-fatigue must include consideration of possible interactions between damage processes associated with creep (e.g., cavitation, grain sliding) and with fatigue (e.g., plastic deformation). It may then happen that for a given test temperature, the time-to-failure for creep-fatigue is much shorter than an "equivalent" stress-rupture loading. This is the case for MA 6000. To give an example, at a temperature of $850{ }^{\circ} \mathrm{C}$, a creep-fatigue test with applied tensile and compressive strain rates of $10^{-5}$ and $10^{-2}\left[\mathrm{~s}^{-1}\right]$, respectively, and a strain amplitude of $0.3 \%$, has a time-to-failure of about 120 hours. The stress needed to cause creep rupture after $120 \mathrm{hrs}$ at this temperature corresponds to $85 \%$ of the actual peak tensile stress applied during the creep-fatigue test. However, only about 20 hrs are spent at this stress or higher during the S-F test, (a stress well above the threshold for creep). Thus, only $1 / 6$ of the creep-rupture time is required for a creep-fatigue loading to cause the equivalent damage based on the applied stress. Figure 8 illustrates the comparison of S-F lifetimes with symmetric cycle fatigue (strain rate of $2 \cdot 10^{-5}\left[\mathrm{~s}^{-1}\right]$ ) at $850^{\circ} \mathrm{C}$. It may be seen from the figure that the asymmetric loading leads a reduction in cyclic life of roughly a factor of 3 . From these observations, it is clear that the net damage accumulation rate is accelerated under conditions which combine slow or constant tensile loading with fully reversed, plastic compression.

One observation made while examining the cavitation damage in MA 6000 caused by creep-fatigue provides a possible clue as to the mechanism by which creep and fatigue damage interact; the maximum pore size reached prior to coalescence never exceeds approximately $2 \mu \mathrm{m}$. This is in contrast with pores developed under constant stress, which attain a diameter of $5-10 \mu \mathrm{m}$ before coalescence $(1,18)$. Although direct measurement of the cavity spacing is made difficult by the fact that regularly spaced, individual pores are rarely seen, it was clearly observed that the cavity spacing is much smaller during creepfatiguc. This is taken to be an indication that cavity nucleation is enhanced by strain reversal. A possible secondary effect could be plastic flattening of pores during compression and subsequently, the acceleration of lateral pore growth. 

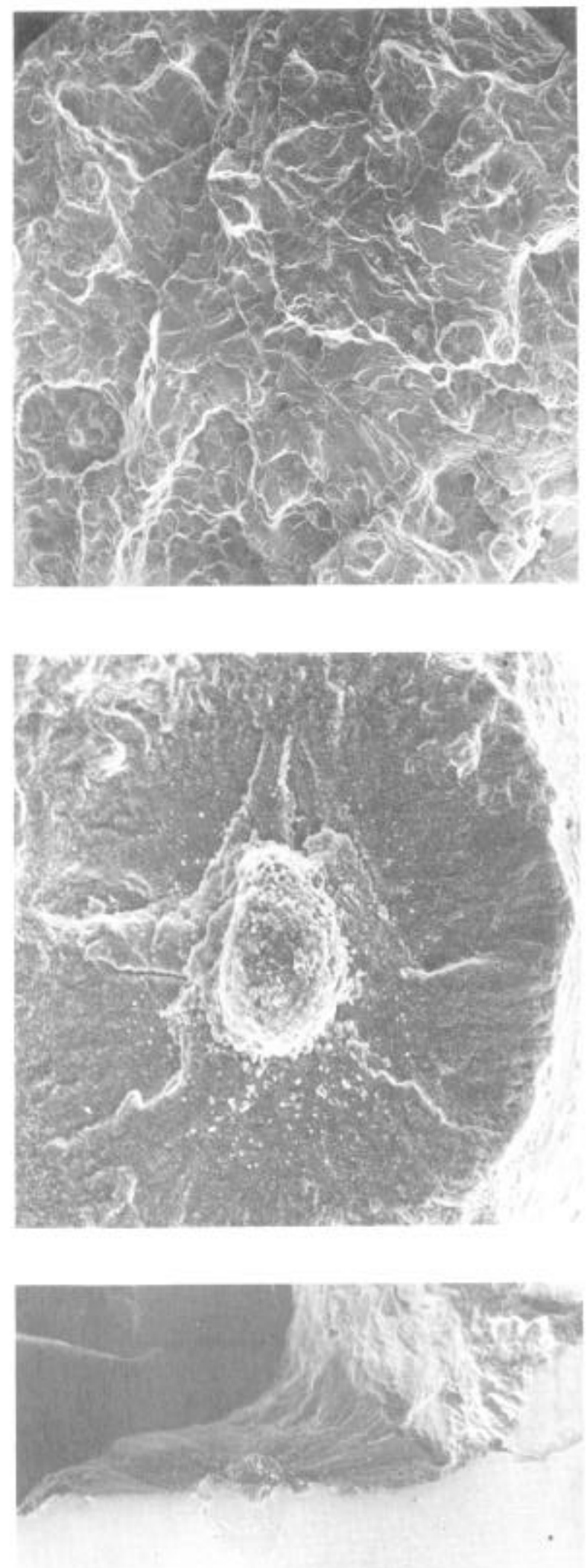

Figure 5: Fracture surface of an MA 6000 sample tested under 'slow-fast' conditions at $850^{\circ} \mathrm{C}$. Cracks initiate internally at fine, included grains, (see figs. 6 and 7). More than 20 individual crack initiation sites may be identified. $\left(\epsilon_{\mathrm{t}}=10^{-5}\left[\mathrm{~s}^{-1}\right], \dot{\epsilon}_{\mathrm{c}}=10^{-2}\right.$ $\left[\mathrm{s}^{-1}\right], \Delta \epsilon / 2=0.3 \%$, failure after 650 cycles)

$1 \mathrm{~mm}$

Figure 6: Detail of crack initiation site taken from the fracture surface of fig. 5 . The tip of an included, fine grain is visible from which a crack has propagated transgranularly through the surrounding macrograin.

$10 \mu \mathrm{m}$

Figure 7: A section taken through a crack initiation site of a sample tested under 'slow-fast' conditions. A crack has initiated on the transverse boundary of a fine, included grain. The outlines of several small grains have been made visible by etching the polished axial section.

$100 \mu \mathrm{m}$ 


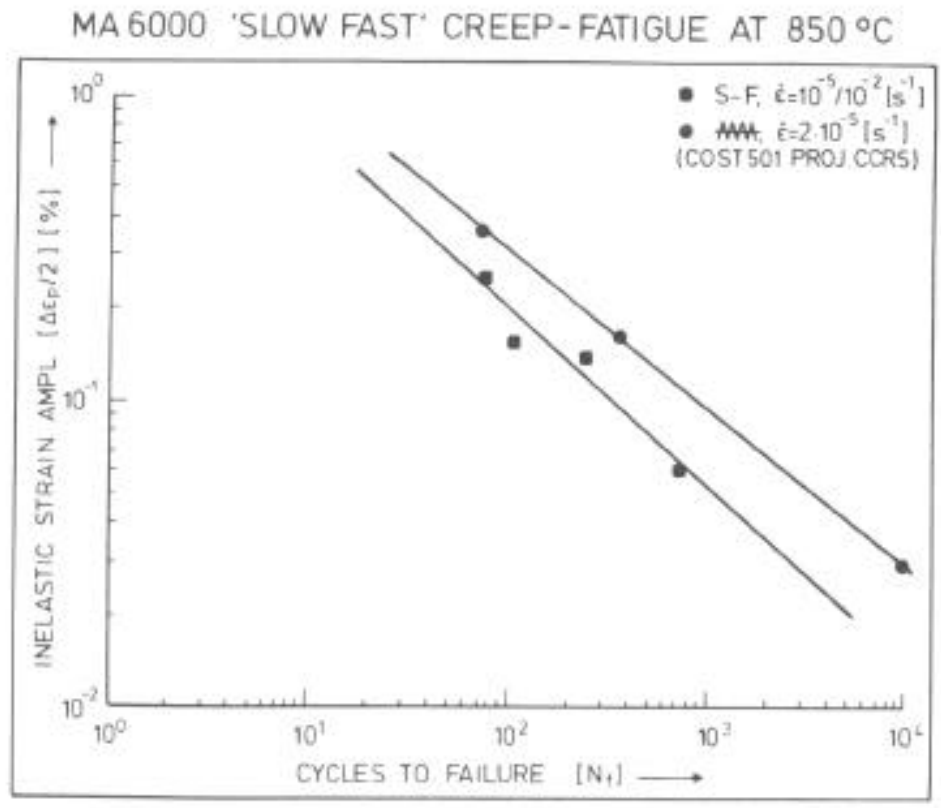

Figure 8: Fatigue resistance of MA 6000 at $850^{\circ} \mathrm{C}$ : S-F cycling results in a severe degradation of the cyclic lifetime in comparison with symmetric LCF.

\section{Creep-fatigue crack propagation}

The crack propagation phase consists of the time between complete cavitation of the transverse fine grain boundary and failure. The greater part of this phase will be spent in transgranular crack extension through the macrograins with the remainder for link-up of planar cracks and subsequent failure. Metallographic investigation has revealed that transgranular cracks are blunted and that quite frequently, pores nucleate and grow ahead of the crack (see figure 9). In addition, precipitate-free zones have been observed between the main crack and individual pores. This evidence suggests that crack advance is controlled by diffusive cavity growth and the fracture of ligaments ahead of the main crack.

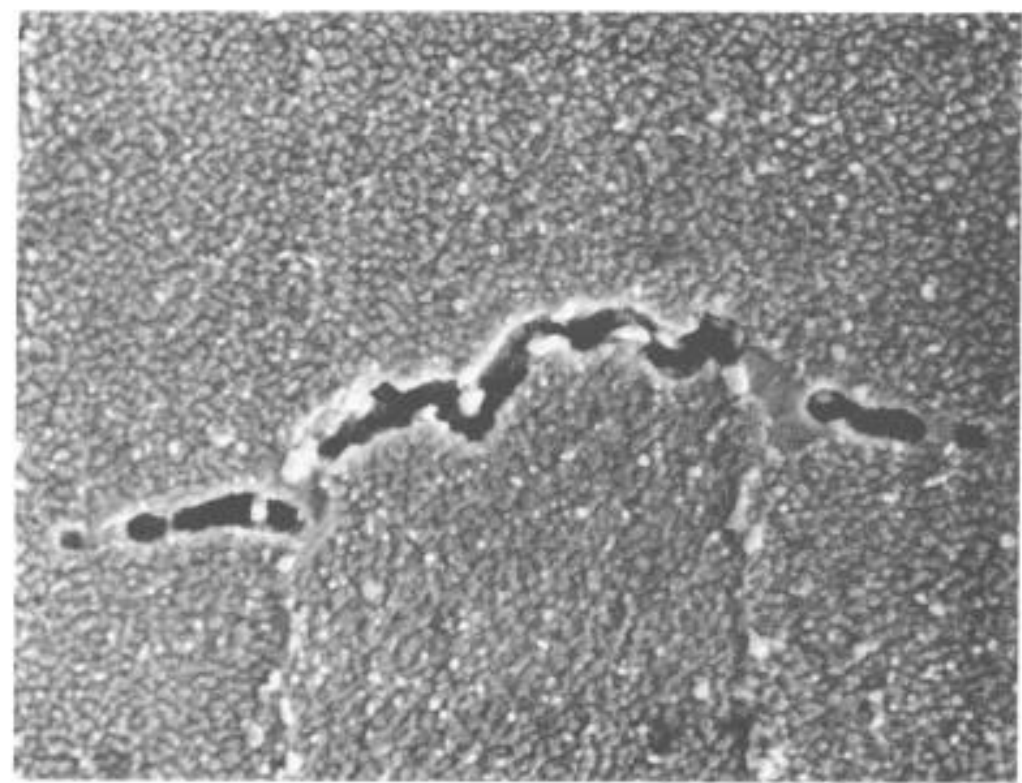

$10 \mu \mathrm{m}$

Figure 9: The transgranular growth of cracks in MA 6000 which initiate at fine grain boundaries during creep-fatigue. Note pores growing ahead of the crack tip and precipitate-free zones.

White particles seen on the grain boundary are the result of an etchant reaction.

$\left(\dot{\epsilon}_{\mathrm{t}}=10^{-5}\left[\mathrm{~s}^{-1}\right], \epsilon_{\mathrm{c}}=10^{-2}\left[\mathrm{~s}^{-1}\right], \Delta \mathrm{t} / 2=0.4 \%\right.$, failure after 242 cycles $)$ 
The linking up of macrograin cracks occurs primarily intergranularly along grain boundaries oriented in the longitudinal direction. Thus, the coalesence of transgranular crack planes is controlled by the spatial distribution of the planes. For the purposes of modelling or lifetime prediction it is necessary to determine the probability that a given average planar crack separation will exist. Decreasing the total number of grain structure inhomogeneities will result in a corresponding improvement in the high temperature creep and creep-fatigue lifetime. Since the next largest defects (e.g. carbonitride particles) are roughly 3 orders of magnitude smaller than the grain defects which are at present responsible for crack initiation, the potential for improving the fatigue resistance by elimination of grain inhomogeneities appears to be substantial.

\section{Summary}

Commercial ODS superalloys have demonstrated improved high temperature fatigue damage resistance in comparison with non-ODS alloys of nearly identical elemental composition. The dispersion improves the fatigue behavior through the inhibition of slip band formation and the resultant suppression of crystallographic microcracking. The creepfatigue properties are enhanced both by the dispersion and by a highly elongated grain structure. It has been shown that recrystallization defects in the form of fine grains are susceptible to the formation of damage. These defects are responsible for the initiation of cracks under LCF and creep-fatigue conditions.

Testing under creep-fatigue conditions leads to a severe degradation of lifetime in comparison with either creep or fatigue alone. The principal mechanism by which the accumulation of creep damage is accelerated by strain reversal appears to be the plastic strain-enhanced cavity nucleation rate. Creep-fatigue tests can be employed to establish the relative density of recrystallisation defects.

Our results indicate that due to the presence of fine grains, the role of the dispersoids in improving the slip character during LCF of oxide-dispersion strengthened superalloys has not yet been exploited. Further progress will depend heavily on our understanding of how recrystallization defects arise and on their eventual elimination.

\section{Acknowledgements}

The authors are especially grateful to C. Weis for assistance with SEM studies and special metallography. Parts of this work have been carried out within the frame of the European Collaborative Programme COST 501. We would like to acknowledge the financial support of the Bundesministerium für Forschung und Technologie in the Federal Republic of Germany under project number O3ZYK1228.

\section{$\underline{\text { References }}$}

1. Zeizinger, H. and Arzt, E., to be published.

2. Arzt, E. and Wilkinson, D.S., "Threshold Stresses for Dislocation Climb Over Hard Particles: The Effect of an Attractive Interaction", Acta metall., 34(10) (1986), 18931898.

3. Arzt, E., "Threshold Stresses for Creep of Dispersion Strengthened Materials", Handbook of Metallic Composites, ed. T.Glasgow and J.D. Whittenberger, (New York, NY: Marcel Dekker, Inc., in press).

4. Arzt, E. and Rösler, J., "The Kinetics of Dislocation Climb Over Hard Particles - II. Effects of an Attractive Particle-Dislocation Interaction", Acta metall., 36(4) (1988), $1053-1060$.

5. Blucher, J.T., Knudsen, P. and Grant, N.J.," The Effect of Strain Rate and Temperature at High Strains on Fatigue Behavior of SAP Alloys", Trans AIME, 245 (1969), 1605-1611.

6. Weber, J.H. and Bomford, M.J., "Comparison of Fatigue Deformation and Fracture 
in a Dispersion-Strengthened and a Conventional Nickel-Base Superalloy", Met Trans, 7 (1976), 435-441.

7. Hoffellner, W. and Singer, R.F., "High Cycle Fatigue Properties of the ODS Alloy MA 6000 at 850 C", Met Trans, 16A (1985), 393-399.

8. Martin, J.W. and Smith, G.C., "The Effect of Internal Oxidation on the Fatigue Properties of Copper Alloys", J. Inst. of Metals, 83 (1955), 153-165.

9. Snowden, K.U., "Some Creep and Fatigue Properties of Dispersed-Oxide-Strengthened Lead", J. Mat Sci, 2 (1967), 324-331.

10. Leverant, G.R. and Sullivan, C.P., "The Effect of Dispersed Hard Particles on the High Strain Fatigue Behavior of Nickel at Room Temperature", Trans AIME, 242 (1968), 2347-2353.

11. Starke, E.A. and Lütjering, G., "Cyclic Plastic Deformation and Microstructure", Fatigue and Microstructure, (Metals Park, OH: American Society for Metals, 1979), $205-243$.

12. Leverant, G.R. and Sullivan, C.P., "The Low Cycle Fatigue of TD-Nickel at 1800 $F^{\prime \prime}$ Trans AIME, 245 (1969), 2035-2039.

13. Kim, Y.G. and Merrick, H.F., "Fatigue Properties of MA 6000E, A Gamma-Prime Strengthened ODS Alloy", Superalloys 1980, ed., J.K.Tien et al (Metals Park, OH: American Society for Metals, 1980), 551-561.

14. Lütjering, G., "Gleitverteilung und Mechanische Eigenschaften Metallischer Werkstoffe", Ber. der Deutschen Luft- und Raumfahrt, Nr.DLR-FB 74-70.

15. Hack, G.A.J., "Fundamentals of Mechanical Alloying", Frontiers of High Temp Materials II, ed., J.S.Benjamin and R.C.Benn (USA: INCO Alloys International, 1983), 3-18.

16. Stephens, J.J. and Nix, W.D., "The Effect of Grain Morphology on Longitudinal Creep Properties of Inconel MA 754 at Elevated Temperatures", Met Trans, 16 (1985), 1307-1323.

17. Schröder, J., "Elektronenmikroskopische Untersuchung des HochtemperaturHärtungs-Mechanismus in einer ODS-Superlegierung", Fortschr.-Ber. VDI, Reihe 5 (1987), Nr.131.

18. Zeizinger, H., "Werkstoffschädigung in einer ODS-Superlegierung durch Hochtemperatur-Ermüdung und Kriechen", Fortschr.-Ber. VDI, Reihe 5 (1987), Nr.121.

19. Elzey, D.M., Ph.D. thesis, University of Stuttgart, 1988, to be published.

20. Merrick, H.F., "The Low Cycle Fatigue of Three Wrought Nickel-Base Alloys", Met Trans, 5 (1974), 891-897.

21. Purushothaman, S. and Tien, J.K., "Slow Crystallographic Fatigue Crack Growth in a Nickel-Base Alloy", Met Trans, 9 (1978), 351-355.

22. Lerch, B.A., Jayaraman, N. and Antolovich, S.D., "A Study of Fatigue Damage Mechanisms in Waspaloy from 25 to $800^{\circ} \mathrm{C}^{\prime \prime}$, Met Sci \& Eng, 66 (1984), 151-166.

23. Schröder, J. and Arzt, E., "Weak Beam Studies of Dislocation-Dispersoid Interaction in an ODS Superalloy", Scripta Metall., 19 (1985), 1129-1134.

24. Ham, R.K. and Wayman, M.L., "The Fatigue and Tensile Fracture of TD-Nickel", Trans AIME, 239 (1967), 721-725.

25. Arzt, E. and Singer, R.F., "The Effect of Grain Shape On Stress Rupture of the Oxide Dispersion Strengthened Superalloy Inconel MA 6000", Superalloys 1984, eet al (Warrendale, PA: The Metallurgical Society, 1984), 369-378.

26. Tekin, A. and Martin, J.W., "Micromechanisms of Creep/Fatigue Interactions in ODS Materials" (Final Report, European Concerted Action COST 501, Project UK2, 1987).

27. Stephens, J.J. and Nix, W.D., "Constrained Cavity Growth Models of Longitudinal Creep of ODS Alloys", Met Trans, 17 (1986), 281-293. 